\section{Colaboración entre organizaciones no gubernamentales y los gobiernos en la reforma del sector de la salud}

Kate Dickson ${ }^{1}$

1 Oficina de Relaciones Externas, Organización Panamericana de la Salud. Dirección postal: 525 Twenty-third Street, NW, Washington, DC 20037, Estados Unidos de América.
El entonces Secretario General de las Naciones Unidas, Boutros Boutros-Ghali, inauguró la 49a Conferencia Anual de las Naciones Unidas (Departamento de Información Pública/organizaciones no gubernamentales), que se celebró el 10 de septiembre de 1996, con las siguientes palabras: “Cada día se pone más de manifiesto que las organizaciones no gubernamentales (ONG) desempeñan un papel importante en el mundo. Yo me he comprometido personalmente a buscar nuevas vías para ampliar y profundizar nuestros vínculos con ellas. Se ha instituido una cultura de consultas. La cooperación entre las agencias de las Naciones Unidas y las ONG a nivel de los países es hoy día algo cotidiano. Las ONG ejercen una función visible y vital en las conferencias de las Naciones Unidas. Las aportaciones, consejos y comentarios procedentes de las ONG constituyen un elemento importante del proceso de toma de decisiones de las Naciones Unidas. Actualmente, nuestra misión consiste en construir sobre los éxitos del pasado, fortalecer nuestra cooperación y buscar nuevas vías para institucionalizar nuestras relaciones".

El 17 de septiembre de 1996 - una semana después de celebrarse esa conferencia-, la Organización Panamericana de la Salud (OPS) llevó a cabo un análisis de sus experiencias acumuladas durante los últimos seis años en el diseño de nuevos mecanismos de diálogo entre gobiernos y ONG y en la planificación y ejecución de actividades derivadas de las prioridades nacionales de salud. El concepto de colaboración, que solo persigue resultados que es más probable obtener mediante el trabajo conjunto que en solitario, es el fundamento de la iniciativa de la OPS. La meta que se busca es alcanzar la salud para todos y por todos.

En la búsqueda de vínculos más efectivos entre gobiernos y ONG, los objetivos operacionales específicos de la OPS han sido proporcionar medios mejores para prestar cooperación técnica y apoyo a los programas en áreas clave tales como la atención primaria de salud; promover y respaldar el intercambio de información y experiencias entre gobiernos y ONG y entre las mismas ONG; coordinar los servicios prestados por gobiernos y ONG con objeto de evitar duplicaciones y dilapidación de recursos, así como ofrecer capacitación técnica y desarrollar planes de acción nacional para la colaboración entre gobiernos y ONG, mediante la traducción a gran escala de experiencias exitosas a pequeña escala. 
Más recientemente, la OPS ha colaborado con los gobiernos miembros en sus esfuerzos por incluir a las ONG en el análisis activo de la filosofía, metas y estrategias de la reforma del sector salud.

La experiencia que están acumulando las ONG también se refleja en el aumento del caudal de asistencia internacional que están canalizando. En la actualidad, se estima que $25 \%$ de la cooperación oficial al desarrollo en el campo de la salud se encauza a través de ONG. Las ONG que interesan a los donantes suelen ser las que trabajan en áreas como la actuación en situaciones de desastres, provisión de servicios, donaciones a las organizaciones de base y a las organizaciones proveedoras de servicios, capacitación y cooperación técnica a organizaciones que desempeñan funciones de desarrollo, investigación e intercambio de información y de formación de redes para cabildeo (1).

A la luz de la mayor importancia que hoy día revisten la democratización y la participación social, los gobiernos están apreciando cada vez más la necesidad de incluir como participantes de pleno derecho a las ONG y las organizaciones comunitarias en todas las etapas del diseño de proyectos, su planificación, seguimiento y evaluación. Además de aumentar el posible impacto y sostenibilidad de un proyecto específico, la inclusión de las ONG en estas etapas, y especialmente en las iniciales, es de capital importancia para fomentar la predisposición de gobiernos y ONG a trabajar en equipo. Ello favorece el diálogo y origina mecanismos de consulta.

Como las actividades de cooperación que realiza la OPS se basan en los países, las representaciones de la Organización se encuentran en una posición clave para facilitar la creación de vínculos entre gobiernos y ONG a nivel nacional. Los representantes están al día de los cambios y tendencias políticos, económicos y sociales del país en que desempeñan su función, y este conocimiento se torna crítico a la hora de determinar la predisposición a colaborar de gobiernos y ONG.

Sin embargo, el ritmo y la forma en que pueden actuar las representaciones para catalizar la colaboración entre gobiernos y ONG varían de un país a otro. Los funcionarios de la OPS deben ser conscientes de las tensiones que generan las relaciones entre gobiernos y ONG, y de que han variado de un país a otro en los últimos 30 años.

\section{FACTORES QUE INHIBEN LAS RELACIONES ENTRE GOBIERNOS Y ONG}

El principal reto que plantea el trabajo con las ONG (básicamente destinado a aumentar el acceso equitativo a los servicios de salud y a garantizar mejores condiciones de salud en la Región) en los próximos años se cifra en superar los principales escollos que han inhibido el desarrollo de relaciones firmes entre gobiernos y ONG. Dichos obstáculos se pueden resumir en tres apartados (2): 1) un ambiente muy politizado y centralizado en el cual las ONG a menudo caen en el lado de la oposición, porque el gobierno o el partido mayoritario se percibe a sí mismo como la única voz legítima del pueblo; 2) la preferencia de las ONG por el aislamiento y su poca disposición a entablar diálogos con el gobierno, y la pobre coordinación entre ambos; 3) el resentimiento de los funcionarios públicos hacia las ONG a consecuencia del alto nivel de acceso a recursos financieros, información y desarrollo profesional de estas últimas, y 4) la percepción de que las ONG no son tan efectivas ni los ministerios, tan eficientes. Las ONG no han podido demostrar en ciertos países su capacidad técnica en administración.

\section{ONG ADECUADAS Y CONSOLIDACIÓN DE RELACIONES CON ELLAS}

Por consiguiente, el determinante más importante de la colaboración exitosa con las ONG en programas específicos es la identificación de ONG apropiadas y la consolidación de las relaciones que se establezcan con ellas. La OPS y los gobiernos deben ser conscientes de las ventajas y oportunidades que ofrecen las ONG y ser capaces de identificar aquellas ONG que pueden contribuir positivamente a una relación de trabajo efectiva. Asimismo, han de garantizar que se utilizan métodos de trabajo rigurosos y que estos conducen al intercambio abierto de información técnica, capacitación, planificación, análisis, ejecución, monitorización y evaluación conjuntos. El ambiente de trabajo debe generar debates francos entre los participantes, y en él la comunicación ha de ser constante y las metas y objetivos marcados, realistas y factibles. Para asegurar que se pueden alcanzar adecuadamente los objetivos, todas las partes han de cerciorarse de la disponibilidad de suficientes recursos para mantener tanto las operaciones como los mecanismos de coordinación y desarrollo de actividades necesarios. Por último, los acuerdos y regulaciones por escrito y las responsabilidades de cada parte sirven para consolidar la colaboración, así como la insistencia en que todas las partes rindan cuentas con claridad.

\section{CRITERIOS DE SELECCIÓN ADECUADOS}

Tal como se señala explícitamente en el documento Principios que rigen las relaciones entre la Organización Panamericana de la Salud y las organizaciones no gubernamentales (3), que fue aprobado por la 
XXXVIII Reunión del Consejo Directivo de la OPS en 1995, las ONG que sean elegibles para entablar debates de política y relaciones operacionales deben cumplir los siguientes criterios: estar registradas legalmente en sus respectivos países; disponer de una experiencia registrada en provisión de servicios, actuación en caso de emergencias, investigación aplicada, organización comunitaria, asistencia educativa y técnica y capacitación, así como haber rendido cuentas adecuadamente en áreas específicas de interés nacional (por ej., salud reproductiva, servicios para enfermedades de transmisión sexual, desarrollo de materiales educativos y de promoción, etc.); poseer personal cualificado para llevar a cabo los planes de acción propuestos en áreas prioritarias; promover enfoques innovadores y técnicamente sólidos de prestación de servicios; considerar las necesidades especiales de grupos seleccionados de la población (inmigrantes, mujeres, adolescentes, etc.); incluir miembros de las poblaciones diana en el diseño y prestación de servicios en su representación; disponer de estructuras administrativas viables y niveles de autoridad, y gozar de solvencia financiera a medio y largo plazo.

\section{LÍNEAS DE ACCIÓN PARA COLABORACIÓN}

Durante los últimos años, la OPS ha desempeñado un papel destacado al facilitar la colaboración entre los gobiernos miembros y las ONG. Al mismo tiempo, la Organización se ha mantenido receptiva a las preocupaciones de los gobiernos miembros respecto a la función que han de ejercer las ONG en los países. Corresponde a los organismos internacionales como la OPS, sus respectivos gobiernos miembros y las ONG trabajar permanente y activamente para alcanzar las metas de atención primaria en todas las áreas técnicas de trabajo. En la sección que sigue se perfilan algunas de las áreas en las que dichas actividades de colaboración técnica se están ampliando para dar cabida a las ONG como tercer actor crítico en el esfuerzo por alcanzar la meta de salud para todos y por todos.

Tras la Cumbre de las Américas, celebrada en diciembre de 1994, la XXXVIII Reunión del Consejo Directivo de la OPS, reunido en Washington, DC, en 1995, aprobó el concepto de reforma del sector salud en su Resolución CD38.R14, e instó a una mayor participación de los actores sociales y las ONG en dicha reforma.

Desde esa fecha, las ONG han sido consultadas cada vez con mayor frecuencia sobre dos temas concretos: su opinión sobre las propuestas de reforma del sector salud de cada país, y las estrategias para lograr mayor participación de las ONG en dicho proceso en cada país (4). Dado que un obje- tivo común de la reforma es facilitar la participación democrática en la salud y el desarrollo, las ONG han comenzado a contribuir notablemente en los aspectos teóricos y prácticos de la salud, como la economía y actividades de generación de ingresos, organización comunitaria, desarrollo social, atención a la salud de los grupos indígenas desde una perspectiva pluricultural, o la salud de las mujeres y de los niños sobre la base de un enfoque de género, así como la investigación. Las ONG tienen la capacidad reconocida de poner en práctica técnicas de trabajo que reflejan un enfoque integrado y que incluyen métodos de participación dirigidos a fortalecer el proceso de reforma del sector de la salud. Otra contribución potencial de las ONG a este proceso es su permanente contacto con la sociedad civil y los diversos actores sociales, lo cual, a su vez, sirve para generar espacios de debate más amplios y canalizar la participación social con miras a garantizar la viabilidad de dicha reforma.

Respecto a la descentralización, la alternativa más ampliamente aceptada ha sido la creación de los sistemas locales de salud, destinada a alcanzar mayores niveles de eficiencia, mejorar la calidad de los servicios y garantizar mayor acceso, no solo a los servicios, sino también a agua potable y saneamiento adecuado para la mayor parte de los grupos de población marginados. Este nuevo énfasis que recae en el "lado de la demanda" — es decir, en ayudar a las comunidades a vertebrar sus preferencias y maniobrar desde una posición negociadora con organismos oficiales- ha galvanizado la aceptación del destacado papel y contribución de las ONG en la salud y el desarrollo, así como la comprensión de que esta nueva función requiere la creación de vínculos distintos entre la comunidad y el sector formal de la salud. Las ONG, relegadas a un segundo plano durante mucho tiempo en el campo de la salud, son cada vez más codiciadas como socios o aliados por los sectores de la salud y social. Hoy día, algunas ONG están sirviendo exitosamente de puente entre estos actores sociales, por medio del fortalecimiento de la toma de decisiones, la gestión y la participación comunitarias, y asegurando la creación de foros que facilitarán este puente.

En lo que atañe a la salud y al medio ambiente, las ONG jugaron una importante baza y ejercieron una notable influencia en la configuración de los resultados obtenidos en la Conferencia de las Naciones Unidas sobre el Ambiente y el Desarrollo (Cumbre para la Tierra) de 1992. El capítulo 22 de la Agenda 21 de esa cumbre indica que los gobiernos deben "invitar explícitamente a las ONG a participar en la formulación de políticas y en la ejecución de programas de desarrollo". Dos años antes, en 1990, los delegados que asistieron a la Cumbre Mundial de la Infancia también habían convenido en la meta 
del acceso universal al agua potable y al saneamiento ambiental en el año 2000, como respuesta necesaria a las inaceptablemente altas tasas de morbilidad y de mortalidad materna total e infantil. Con objeto de identificar enfoques factibles técnicamente para reducir la incidencia de enfermedad y muerte prematura mediante la prevención de enfermedades, la OPS favorece un enfoque dual, que incorpora a las comunidades y participa en la valoración y gestión de los riesgos para la salud ambiental. La Iniciativa Colaboración ONG-Gobierno busca, por consiguiente, promover la integración de ONG nacionales e internacionales en el diseño y la ejecución de programas nacionales geográficamente específicos. Actualmente, se están creando redes nacionales de ONG que cuentan con experiencia registrada en la instalación de sistemas de abastecimiento de agua a la comunidad y proyectos de saneamiento ambiental, residuos sólidos, aguas residuales, higiene alimentaria, polución del aire, desecho de materias peligrosas y tóxicas y de salud ocupacional.

La Iniciativa Colaboración ONG-Gobierno de la OPS se complementa estrechamente con la Iniciativa de Salud de los Pueblos Indígenas de las Américas y con la Resolución $\mathrm{V}$, que fue aprobada en la XXXVII Reunión del Consejo Directivo de la OPS en septiembre de 1993 con el fin de que los gobiernos de la Región promuevan dicha iniciativa $(4,5)$. La naturaleza y filosofía del actual programa colaborativo se han consolidado a fin de facilitar el diseño de estrategias destinadas a transformar los sistemas nacionales de salud y desarrollar modelos alternativos de atención a nivel local.

El sida, la tuberculosis, el dengue, la malaria y el cólera ofrecen ejemplos adicionales concretos de enfermedades infecciosas que suponen retos globales, que solo pueden ser resueltos por personas pertenecientes a diversas organizaciones que trabajen conjuntamente (6). La tuberculosis, como muchas otras enfermedades nuevas y de reciente reaparición, representa una amenaza creciente para la salud pública mundial. Países como Bolivia, Guatemala y Paraguay están trabajando con ONG internacionales y nacionales para mejorar los recursos destinados a la capacitación en tareas de educación y control de la tuberculosis, así como para aumentar el número de servicios de detección y tratamiento de pacientes con esta enfermedad. No obstante, en muchos países las ONG que operan en el sector de la salud podrían desempeñar un papel mucho mayor en el control de la tuberculosis. Un reto definitivo en el trabajo con múltiples socios será asegurar que se alcanzan acuerdos mutuos en las normas de atención, con objeto de que las amenazas que surjan para la salud, como la resistencia a los antibióticos, no se potencien sino que se prevengan mediante actividades de control ampliadas.
Los esfuerzos de prevención del sida realizados hasta la fecha confirman que las ONG y las organizaciones basadas en la comunidad desempeñan una función cardinal en la prevención, el control y el tratamiento de esta enfermedad. Estas organizaciones fueron, además, las primeras en dar respuesta a la epidemia causada por el virus de la inmunodeficiencia humana, tanto en países industrializados como en desarrollo, aunque en menor medida en estos últimos. Es notorio que las ONG que cooperan en actividades de prevención del sida y atención de los pacientes infectados ofrecen las ventajas de ser efectivas en función del costo, responder a las nuevas necesidades y tener acceso a comunidades seleccionadas tales como los jóvenes, mujeres, inmigrantes, prostitutas, camioneros, presos, etc. Hoy día, para muchas comunidades marginadas con limitado acceso a los servicios gubernamentales, las ONG representan su única esperanza para prevenir y tratar el sida. Como el número de enfermos de sida e infectados asintomáticos es todavía relativamente bajo en relación con las proyecciones realizadas para el futuro cercano, las ONG ofrecen la ventaja de disponer de un compás de espera, que les permitirá prepararse para satisfacer nuevas necesidades que pueden anticiparse. Sin embargo, en pocas ONG se entiende la magnitud del futuro impacto del sida en la prestación de servicios de salud. Para que nuestras comunidades sean capaces de responder efectiva y humanamente en los próximos años, es crucial que las organizaciones de servicios trabajen en equipo.

Las ONG también ocupan un lugar prominente en todas las cumbres internacionales que se han celebrado en los años ochenta y noventa, incluidas la Cumbre Mundial de la Infancia, en la cual se analizaron las infecciones respiratorias agudas y las enfermedades diarreicas como las dos causas principales de muerte de niños menores de 4 años, seguidas por la malnutrición. La Convención de los Derechos del Niño proporcionó lo que se considera que será el contexto de trabajo del próximo siglo. Empero, las lecciones aprendidas desde 1990 en la consecución de esas metas apuntan hacia la necesidad de disponer de enfoques más efectivos, como la mayor integración de los esfuerzos que se realizan en el campo de la salud, así como la importancia creciente que debe otorgarse a la participación de la comunidad (7). Habida cuenta de las ventajas comparativas que ofrecen estas dos áreas, las ONG deberían incluirse sistemáticamente, tanto a nivel local como nacional, en la planificación y ejecución de las estrategias revisadas de los países.

El mejoramiento del estado nutricional de las familias demanda tiempo, atención, servicios de apoyo y pericia en la prestación de servicios. Las ONG acostumbran participar en más intervencio- 
nes dirigidas a necesidades básicas, como la nutrición adecuada, los servicios básicos de salud y el ambiente saludable. Las áreas de trabajo correspondientes incluyen el mejoramiento de la producción agrícola y la horticultura, el uso adecuado de pesticidas y medicamentos en veterinaria, la educación en tecnologías adecuadas, el acceso a agua potable y servicios de saneamiento, la promoción de la lactancia materna, y la mejora de la situación de las mujeres que viven en zonas rurales y urbanas marginales. Las ONG son aliados ideales para reducir la morbilidad y mortalidad en la niñez, mediante el apoyo que prestan a las actividades de control y prevención de las enfermedades diarreicas, las respiratorias agudas y la malnutrición.

En cuanto a las campañas de vacunación, la ONG Rotario Internacional fue uno de los principales aliados de la OPS en la iniciativa de erradicación de la poliomielitis, aportando fondos para comprar vacunas y llevando a cabo actividades de movilización social durante los días de vacunación nacional. En Bolivia, Colombia, Cuba, Ecuador, Nicaragua, Perú y Uruguay, esta organización participó en numerosas actividades, como seminarios, ruedas de prensa, mesas redondas, control y vigilancia de enfermedades, y mantenimiento de la cadena de frío. El Rotario Internacional también ha hecho una notable labor en la ejecución de programas contra el sarampión en todo el Caribe de habla inglesa. La iniciativa de colaboración entre la OPS y las ONG trata de remedar esta exitosa experiencia diseñando un plan de acción mediante el cual se utilizarán consultorios privados y la experiencia en comunicación y educación de las ONG en la campaña de 5 años destinada a interrumpir la transmisión del virus del sarampión (8).

Por medio de la amplia colaboración con ONG en todo el hemisferio, el Programa Mujer, Salud y Desarrollo de la OPS está promoviendo y respaldando programas nacionales y regionales que intentan responder al reto que supone la equidad de géneros en las esferas de la salud y el desarrollo humano. Los esfuerzos se están concentrando en estimular a las mujeres y a sus parejas a tomar decisiones informadas en relación con la sexualidad, el matrimonio y la procreación; realizar investigaciones epidemiológicas y sociales oportunas y actuar en los aspectos desatendidos de la salud de la mujer, y facilitar la comunicación y el establecimiento de redes de información entre mujeres, proveedores de servicios de salud y los responsables de las decisiones políticas.

Junto al tema de las políticas saludables se encuentra la preocupación puesta de manifiesto por los gobiernos miembros de la OPS relativa a la violencia doméstica y urbana. Mucho queda por hacer y puede acometerse con éxito mediante alianzas intersectoriales dinámicas, que incluyan ONG y otros grupos con experiencia en este campo, en la recreación de los adolescentes, prevención del embarazo de adolescentes, y enfermedades de transmisión sexual, incluida la infección por el virus de la inmunodeficiencia humana y el sida.

En junio de 1996, la OPS se comprometió a respaldar y canalizar la experiencia de las ONG en educación informal, así como acometer actividades de prevención encaminadas a reducir la prevalencia de enfermedades no transmisibles, cuando estableció relaciones oficiales con la Federación Internacional de la Diabetes en las Américas. Anteriormente, el 7 de marzo de 1992, un grupo de trabajo para el desarrollo de asociaciones con miembros de dicha federación había declarado lo siguiente: "Los intereses de toda la gente relacionada con la diabetes, ya sea que vivan o trabajen con la enfermedad, pueden satisfacerse mejor al unirse en una asociación nacional. La asociación incluye personas que tienen la enfermedad y sus familiares, así como profesionales de la salud, científicos, médicos y otro personal de apoyo a la salud. El contar con una sola asociación nacional de diabetes en cada país asegurará el tener una sola voz en todos los asuntos relacionados con ella, recursos (económicos y humanos) que no serán divididos y dispersados y trabajo que no será duplicado" (9).

Por último, respecto a la colaboración entre ONG y gobiernos en programas y proyectos de emergencias, la mayor parte de las organizaciones operativas, como el Fondo de las Naciones Unidas para la Infancia, el Programa Mundial de Alimentos, la OPS/OMS y el Alto Comisionado de las Naciones Unidas para los Refugiados, confían cada vez más en la capacidad de las ONG nacionales e internacionales para desarrollar proyectos y programas de emergencia.

Durante los últimos años se han acumulado y documentado muchos conocimientos sobre el tema abordado en este trabajo. Esto sirve para situar la cooperación técnica que presta la OPS en una posición de liderazgo respecto a otros organismos internacionales en el sentido de servir de puente a las brechas percibidas en cuanto a la salud y el desarrollo entre las diversas instituciones, promover el diálogo permanente y crear redes estructurales que vertebren la colaboración entre ONG y gobiernos en sectores específicos de la salud y el desarrollo. Los modelos que se han desarrollado, las lecciones aprendidas y el intento manifiesto de incorporar a las ONG -concebidas como parte singular e importante de la sociedad civil- en los servicios de salud y en los procesos de reforma del sector salud servirán, sin lugar a dudas, de ejemplos prácticos que pueden replicarse y acomodarse a la situación económica, política y social nacional concreta en muchos otros países de la Región de las Américas. 


\section{SYNOPSIS}

\section{Collaboration between nongovernmental organizations and governments in health sector reform}

One of the most prominent current trends is the vital and increasingly visible role played by nongovernmental organizations (NGOs) in the world in general and in the activities and conferences sponsored by the United Nations (UN). Given these circumstances, part of the mission of PAHO is to strengthen the ties between governments and NGOs through provision of technical cooperation and support in priority program areas, such as health care, and facilitation of the exchange of information and experiences. This report examines different lines of action designed to improve collaboration between NGOs and governments in the area of health sector reform.

\section{REFERENCIAS}

1. Brown LD, Korten DC. Understanding voluntary development organizations: guidelines for donors. Washington, DC: Institute for Development Research; 1989:10-11.

2. Chauvin J. Study for profiling the characteristics for effective NGO/government collaboration for EPI and primary health care. Ottawa: Canadian Public Health Association; 1995.

3. Organización Panamericana de la Salud. Principios que rigen las relaciones entre la Organización Panamericana de la Salud y las organizaciones no gubernamentales. Washington, DC: OPS; 1995. (Documento aprobado por la XXXVIII Reunión del Consejo Directivo de la OPS).

4. Centro de Estudios de Población y Paternidad Responsable. Proyecto de análisis y promoción de políticas de salud. Informe del seminario-taller: "Las ONG y la reforma del sector salud en el Ecuador". Quito: CEPAR; 1996:1.

5. Organización Panamericana de la Salud. Informes Finales. 110a y 111a Reuniones del Comité Ejecutivo de la OPS. XXXVII Reunión del Consejo Directivo de la OPS. XLV Reunión, Comité Regional de la OMS para las Américas. Washington, DC: OPS 50-52. (Documento oficial 260).

6. Department of Health and Human Services, Centers for Disease Control and Prevention. Addressing emerging infectious diseases threats; a prevention strategy for the U.S. Department of Health and Human Services, Centers for Disease Control and Prevention. Atlanta; Georgia: Department of Health and Human Services, Centers for Disease Control and Prevention; 1994:1.
7. World Health Organization. Report of the UNICEF-WHO Joint Committee on Health Policy. Special session, Geneva, 15-16 May, 1996. Geneva: WHO; 1996:3. (Document JCHPSS/96.5).

8. Pan American Health Organization. Rethinking international technical cooperation in health. Technical discussions. Background document. Experiences in working with non-traditional partners. Washington, DC: PAHO; 1996.

9. International Diabetes Federation, Task Force on Member Association Development. La unión hace la fuerza. Budapest: International Diabetes Federation, Task Force on Member Association Development; 1992. 